\title{
Perfil do Programa do Doutorado Interdisciplinar em Ciências Humanas da UFSC
}

\section{Profile of the Interdisciplinary Doctoral Program in the Human Sciences at UFSC}

\author{
Naira Tomiello ${ }^{1}$ \\ Joana Maria Pedro
}

\section{RESUMO}

Este estudo sustenta que não basta alegar a importância e a essencialidade da interdisciplinaridade, é necessário analisá-la, a fim de compreender os seus desafios e as suas conquistas. No caso do Programa de Pós-Graduação Interdisciplinar em Ciências Humanas (PPGICH), parte-se dos questionamentos: quem são os atores que fazem parte da construção interdisciplinar? Como a construção do conhecimento pode ser recortada a partir da distinção das Áreas de Concentração e a partir dos temas mais recorrentes? Definiu-se como objetivo geral deste artigo caracterizar o perfil do Programa de Doutorado Interdisciplinar em Ciências Humanas. Trata-se de uma pesquisa de abordagem quantitativa-descritiva, com o propósito de descrever as características do fenômeno em estudo. O procedimento de coleta de dados foi por meio de pesquisa documental. A caracterização do perfil permite pontuar alguns obstáculos, reconhecer a trajetória que vem sendo construída, comparar e subsidiar possíveis mudanças nas estratégias do curso, assim como analisar em que ponto o programa interdisciplinar se diferencia dos demais programas disciplinares.

Palavras-chave: Interdisciplinaridade. Caracterização do Perfil. PPGICH.

\section{ABSTRACT}

This study is based on the assumption that it is not sufficient to affirm the importance of interdisciplinarity, it must be analyzed in order to understand its challenges and achievements. In the case of the Interdisciplinary Graduate Program in Human Sciences (PPGICH), the following questions are raised: who are the actors who are part of the interdisciplinary construction? How can the construction of knowledge be focused, based on the distinction between the fields of concentration and the most common issues? The general objective of this article is to characterize the profile of the Interdisciplinary Doctoral Program in the Human Sciences through a quantitative and

\footnotetext{
${ }^{1}$ Doutoranda no Programa de Pós-Graduação Interdisciplinar em Ciências Humanas (UFSC), Mestre em Administração de Empresas (UDESC), Bacharel em Ciências Sociais (UFSC) e Licenciada em Filosofia (UCS). Bolsista pelo CNPq a partir de março de 2009. nairatomiello@uol.com.br

${ }^{2}$ Doutora em História Social pela Universidade de São Paulo. Fez pós-doutorado na França, na Université d'Avignon. Atualmente é professora titular da Universidade Federal de Santa Catarina do Programa de Pós-Graduação em História e do Programa de Pós-Graduação Interdisciplinar em Ciências Humanas da UFSC, do qual é a Coordenadora. joanamaria.pedro@gmail.com
} 
descriptive approach to describe the characteristics of the phenomenon being studied. Documentary research was conducted to collect data. The characterization of the profile allows indicating some obstacles, recognizing the trajectory that has been built, to compare and support possible changes in the strategies of the course, as well as analyze how the interdisciplinary program is distinct from other disciplinary programs.

Key words: Interdisciplinarity. Characterization of the Profile. PPGICH.

\section{INTRODUÇÃO}

A implementação e a consolidação de programas interdisciplinares têm-se constituído um grande desafio. Entre as razões, o coordenador da Área Interdisciplinar da Capes $^{3}$, Arlindo Philippi Jr., destaca que essa área exige um tempo maior de preparação e maturação, em virtude de uma certa convergência de linguagem entre as diferentes áreas de conhecimentos. E, para ele, a ciência ruma inexoravelmente a uma maior atuação interdisciplinar. (CAPES, 2009). Paviani (2008, p. 105) reforça tal relevância, expressando que a época atual consiste na "era da interdisciplinaridade". Entretanto, o autor salienta que não basta alegar o conceito, é preciso que ele seja explicitado e efetivado e acrescenta: "não basta repetir slogans, é necessário analisálos em seus detalhes". (PAVIANI, 2008, p. 107). Desse modo, definiu-se como propósito deste estudo captar parte do desafio da construção interdisciplinar, mediante a caracterização quantitativa do perfil do Programa de Pós-Graduação Interdisciplinar em Ciências Humanas da Universidade Federal de Santa Catarina.

A abordagem interdisciplinar altera as proposições curriculares e as relações institucionais. A postura interdisciplinar propicia a formulação de hipóteses mais criativas e exige "ter coragem e disponibilidade para deixar o porto seguro das certezas e conviver com as diferenças e a pluralidade de pontos de vista". (MALHEIROS; PHILIPPI Jr., 2000, p. 151). Os resultados positivos de projetos interdisciplinares incluem uma mudança de atitudes dos envolvidos; reconhecem a necessidade de buscar novos métodos; ressaltam a agilidade em compreender as necessidades e a efetiva participação de diferentes atores sociais envolvidos em gestão local. Os autores concluem que a efetivação do processo interdisciplinar depende de uma política, que

\footnotetext{
${ }^{3}$ Coordenação de Aperfeiçoamento Pessoal de Nível Superior - CAPES.
} 
inclui reforma estrutural e metodológica no sistema de ensino; do desenvolvimento de mecanismos econômicos financiadores; da definição de linhas de prioridades; e do estabelecimento de um processo de avaliação que permita acompanhar e corrigir desvios.

A importância da interdisciplinaridade é recortada por Klein (1990, p. 41) ao apresentar cinco fatores estudados pela Organização de Cooperação e Desenvolvimento Econômico (OCDE) que tornam tal abordagem essencial: a) Desenvolvimento da ciência (emergência de novos campos de conhecimento e complexidade dos temas estudados); b) Demanda dos estudantes (contra a fragmentação do conhecimento e divisões artificiais entre conhecimento e a realidade); c) Problemas operacionais e administrativos das universidades (diferentes grupos poderiam compartilhar espaços e recursos); d) Necessidade de treinamento (formação compatível com a flexibilidade das demandas profissionais); e) Demandas sociais (complexidade dos problemas não pode ter soluções restritas a disciplinas isoladas).

O Programa de Pós-Graduação Interdisciplinar em Ciências Humanas da Universidade Federal de Santa Catarina iniciou suas atividades em 1995, com o propósito de desenvolver estudos voltados ao meio ambiente, em nível de doutoramento. Em 1998, transformou-se em Doutorado Interdisciplinar em Ciências Humanas, abrangendo as áreas de Condição Humana na Modernidade ( $\mathrm{CHM}$ ) e Sociedade e Meio Ambiente (SMA). A partir do ano de 2000, o Programa assumiu a constituição atual, acrescentando Estudos de Gênero (EGE) como uma terceira área de concentração ${ }^{4}$. Dessa trajetória, que incluiu, entre outros, a redefinição do foco e o acréscimo de novas linhas de pesquisas, o Programa conquistou, na última avaliação da CAPES, outubro de 2007, o conceito 5.

Entende-se que tal trajetória deve ser investigada a partir dos questionamentos: quem são os atores que fazem parte da construção interdisciplinar? Como a construção do conhecimento pode ser recortada a partir da distinção das áreas de concentração? Quais são os temas mais recorrentes no Programa?

\footnotetext{
${ }^{4}$ Cada Área de Concentração, CHM, SMA e EGE, subdivide-se em Linhas de Pesquisas. No link $<$ http://www.cfh.ufsc.br/ dich/index.htm> estão presentes as respectivas ementas, representantes docentes e discentes.
}

Cad. de Pesq. Interdisc. em Ci-s. Hum-s., Florianópolis, v.10, n.97, p. 5-26, jul./dez. 2009 
A fim de delimitar o campo de investigação, optou-se pelo reconhecimento dos atores e da construção do conhecimento a partir das seguintes variáveis: teses defendidas até 2008; formação acadêmica do corpo docente e dos egressos (até 2008); quadro de orientações; e palavras-chave recorrentes nas teses. Definiu-se como objetivo geral deste artigo caracterizar o perfil do Programa de Doutorado Interdisciplinar em Ciências Humanas. Para atender ao objetivo geral e observar a delimitação estabelecida, propõe-se, como objetivos específicos, identificar o número de teses defendidas, por área de concentração, de 1999 a 2008; levantar a distribuição do número de teses por orientador e co-orientador; descrever a formação acadêmica do corpo docente e dos egressos; conhecer a recorrência de temas abordados nas teses, a partir das palavras-chave.

Quanto ao procedimento metodológico, trata-se de uma pesquisa de abordagem quantitativa-descritiva, com o propósito de descrever as características do fenômeno em estudo. O procedimento de coleta de dados foi por meio de pesquisa documental. O universo, amostra e a fonte de pesquisa serão especificados em cada tópico deste trabalho. $O$ tratamento dos dados será por análise de frequência, apresentada em gráficos e tabelas.

\section{TESES DEFENDIDAS NO PROGRAMA}

Os dados para a elaboração dos gráficos foram obtidos no site do Programa ${ }^{5}$. No gráfico 01 pode-se observar a diferença entre o número de ingressos desde a existência do curso, 1995, e o número de egressos até o ano de 2008. O total de ingressos soma cento e vinte e oito (128) alunos, sendo que setenta e quatro (74) já defenderam suas teses.

\footnotetext{
${ }^{5}$ Os gráficos elaborados para este artigo foram disponibilizados no site do Programa, que está sendo reformulado.
} 


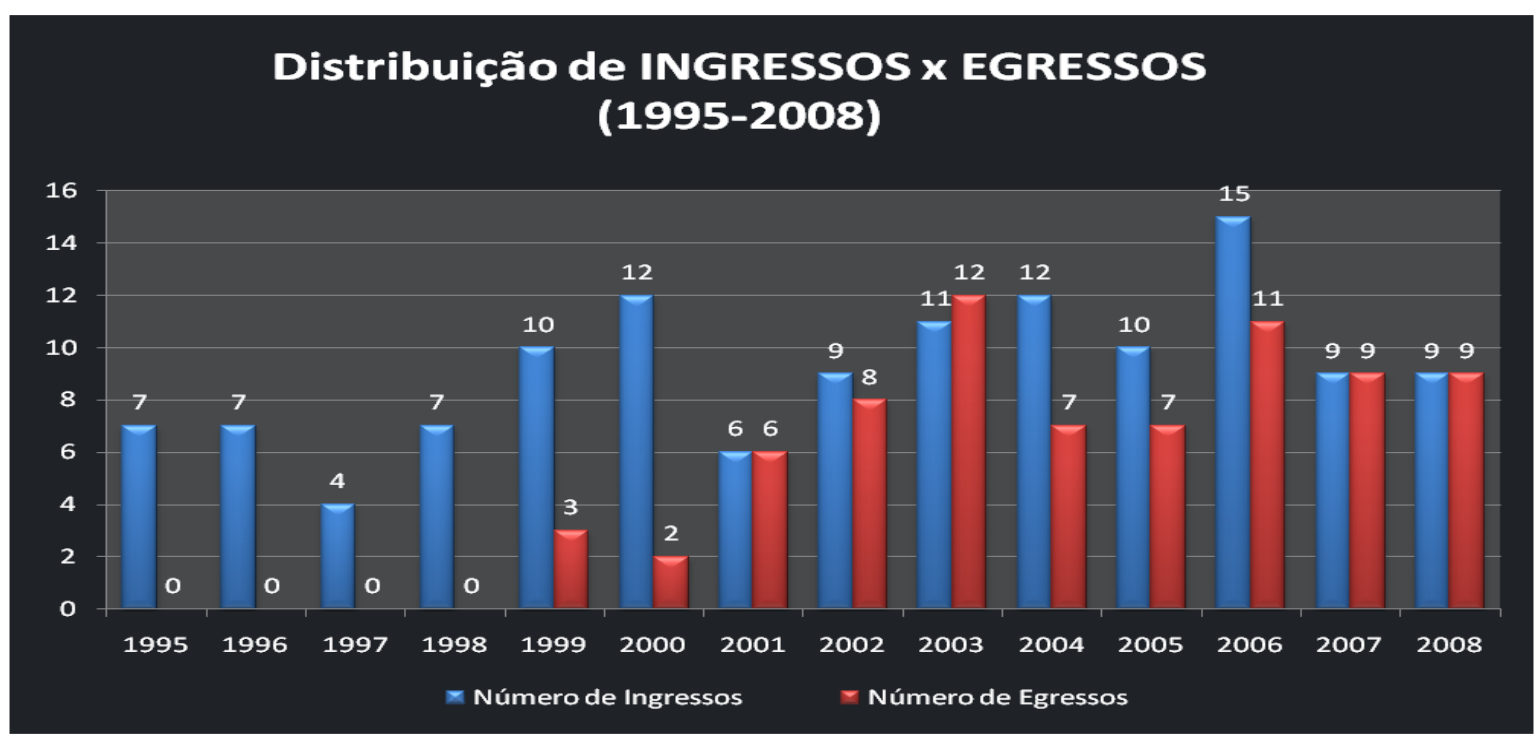

Gráfico 01: Comparativo entre o número de ingressos e egressos Fonte: Elaborado a partir do site do PPGICH - UFSC (2008).

Nos quatorze (14) anos (1995-2008) dispostos no gráfico, há uma média de nove (9) ingressos por ano. Nos anos de 2000, 2003, 2004 e 2006, houve um número de ingressos acima de dez (10) alunos. Destaca-se o ano de 2006, que recebeu quinze (15) novos estudantes. Não cabe a este artigo explicar, mas é preciso questionar quais são as variáveis que justificam diferenças, tais como a queda de $50 \%$ no número de ingressos entre os anos de 2000 e 2001, ou um aumento de $150 \%$, se comparado com os anos de 2001 e 2006.

Quanto aos egressos, considerando o intervalo de dez (10) anos (1999-2008), a média corresponde a sete (7) alunos que defenderam a tese. Se for considerado o número de ingressos, no mesmo período, a média para estes passa a ser dez (10) alunos ingressantes. Assim, dentro de um mesmo período (1999-2008), a média de ingressos é dez (10) e de egressos, sete (7). Tal diferença justifica-se, prioritariamente, por novas oportunidades de trabalhos e por motivos de doença. É preciso estar atento à projeção dessa diferença, a fim de justificá-las quanto ao número de desistências, trancamentos, prorrogações etc., bem como a sua repercussão na avaliação do curso.

O gráfico 02 mostra a distribuição das setenta e quatro (74) teses defendidas por área de concentração, sendo que do total, $54 \%$ estão na área de Sociedade e Meio Ambiente; $27 \%$ na área de Condição Humana e 19\% em Estudos de Gênero. 


\section{Distribuição de TESES por ÁREA DE CONCENTRAÇÃO}

(1999- 2008)

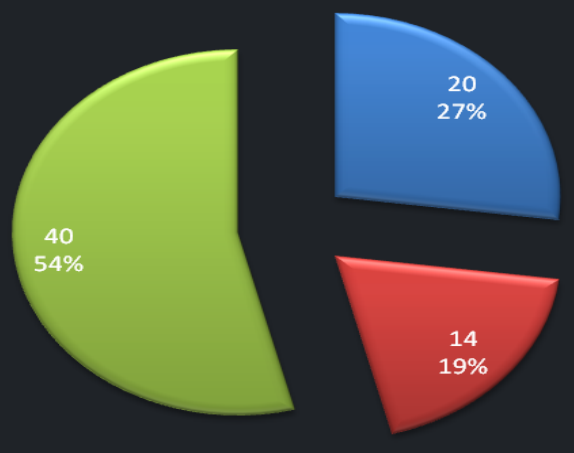

Gráfico 02: Total de Teses Defendidas por Área de Concentração Fonte: Elaborado a partir do site do PPGICH - UFSC (2008).

Justifica-se o percentual maior de teses defendidas na área de Sociedade e Meio Ambiente, tendo em vista o histórico de formação do curso, que registra o início de suas atividades em tal área de concentração. O gráfico 03 traz a comparação do número de defesas por área de concentração e também por ano.

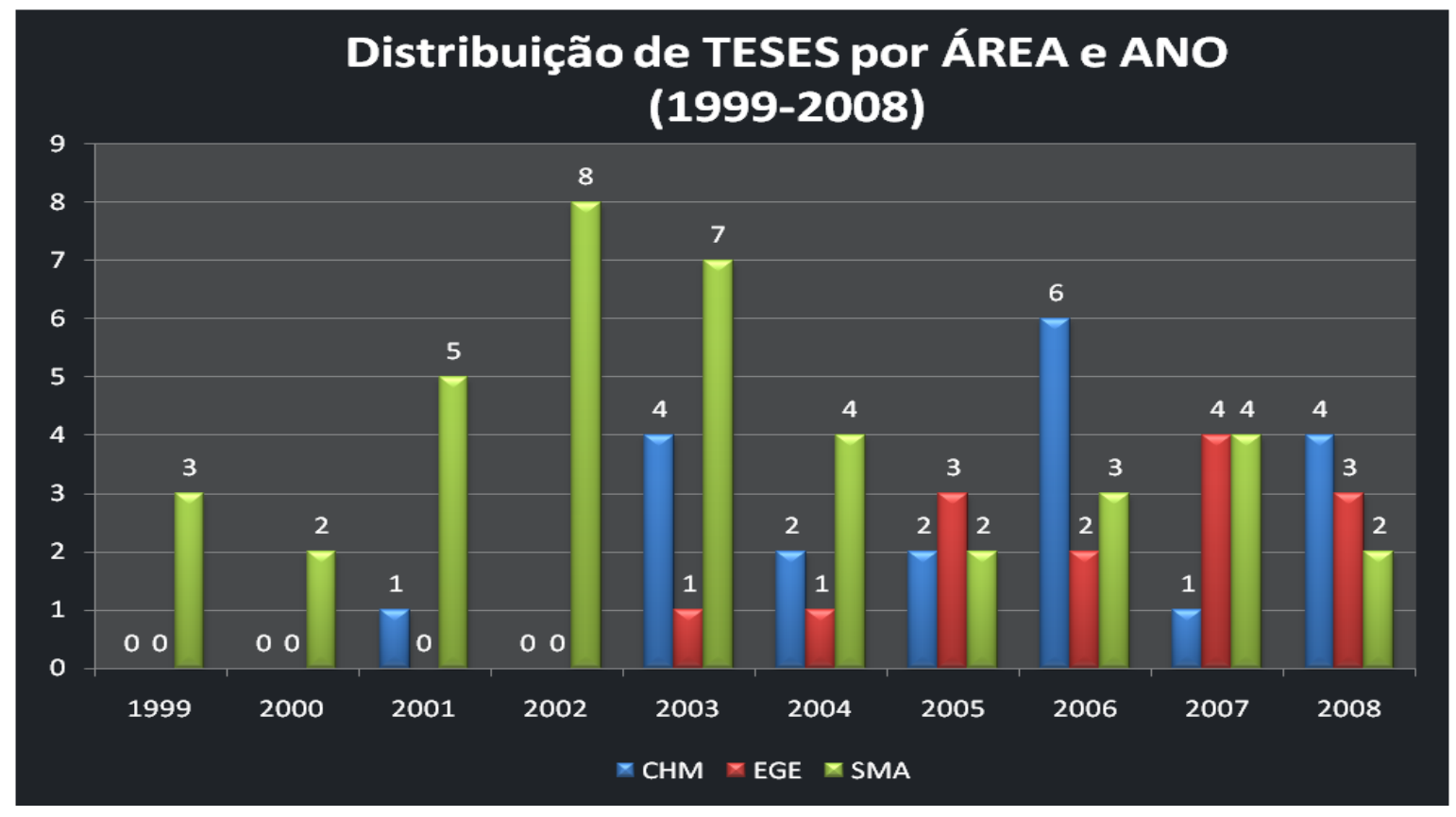

Gráfico 03: Comparativo do número de defesas por área de concentração e ano. Fonte: Elaborado a partir do site do PPGICH - UFSC (2008). 
Percebe-se que o predomínio de defesas na área de Sociedade e Meio Ambiente ocorreu até o ano de 2004. A partir desse ano, há uma irregularidade, com destaque para o ano de 2006, com seis (6) defesas na área de Condição Humana na Modernidade.

É importante lembrar que o Programa deixa de ser focado em "Sociedade e Meio Ambiente" e torna-se doutorado em "Ciências Humanas", seguindo uma mudança gradual, conforme a disposição a seguir:

\begin{tabular}{c|c|c}
1995 & 1998 & 2000 \\
\hline Sociedade e Meio Ambiente & $\begin{array}{c}\text { Condição Humana na } \\
\text { Modernidade }\end{array}$ & Estudos de Gênero
\end{tabular}

O acréscimo de novas áreas de concentração ocorreu na gestão da professora Dra. Maria Nascimento-Shulze e justifica-se, inicialmente, pelos constantes problemas que a palavra "meio ambiente" suscitava diante do comitê de avaliação da CAPES $^{6}$ e pelas mudanças no perfil dos novos professores ${ }^{7}$.

O item Teses Defendidas no Programa contribui ao dispor os números que podem revelar tendências, disparidades, equilíbrios, prever situações indesejadas ou apropriadas. É importante acompanhar os dados, a fim de verificar como se comporta o novo quadro que vem se configurando, sem o predomínio da área de Sociedade e Meio Ambiente. Pode-se comparar, por exemplo, o número de ingressos e egressos por área de concentração. Assim, um estudo de demanda, seleção e conclusão poderia revelar especificidades importantes para o investimento [estrutural, financeiro e humano] em determinada área.

\footnotetext{
${ }_{7}^{6}$ Os avaliadores da CAPES exigiam cientistas naturais no quadro de docentes.

7 A história do PPGICH foi narrada no artigo pelos professores Dra. Joana Maria Pedro e Dr. Luiz Fernando Scheibe, cujo título é "Uma experiência de construção coletiva: o Programa de Pós-Graduação Interdisciplinar em Ciências Humanas da Universidade Federal de Santa Catarina". Artigo é inédito e será publicado pela CAPES.
}

Cad. de Pesq. Interdisc. em Ci-s. Hum-s., Florianópolis, v.10, n.97, p. 5-26, jul./dez. 2009 


\section{ORIENTAÇÃO E CO-ORIENTAÇÃO}

A existência do papel do orientador e co-orientador justifica-se para reforçar o caráter interdisciplinar da tese, tendo em vista que o Regimento do Programa prevê que os professores parceiros na orientação tenham especialidades diferentes. (PPGICH, 2009). Este item é importante para identificar quais são os professores que têm ou tiveram uma atuação frequente ou esporádica no Programa. Os dados foram retirados do site, sendo que o universo é de cinqüenta e seis (56) de professores que já orientaram ou co-orientaram as teses. Destes, vinte e seis (26) atuaram como orientadores para as setenta e quatro (74) teses. No gráfico 04, é possível ver a relação dos nomes dos orientadores e seus respectivos números de orientações concluídas.

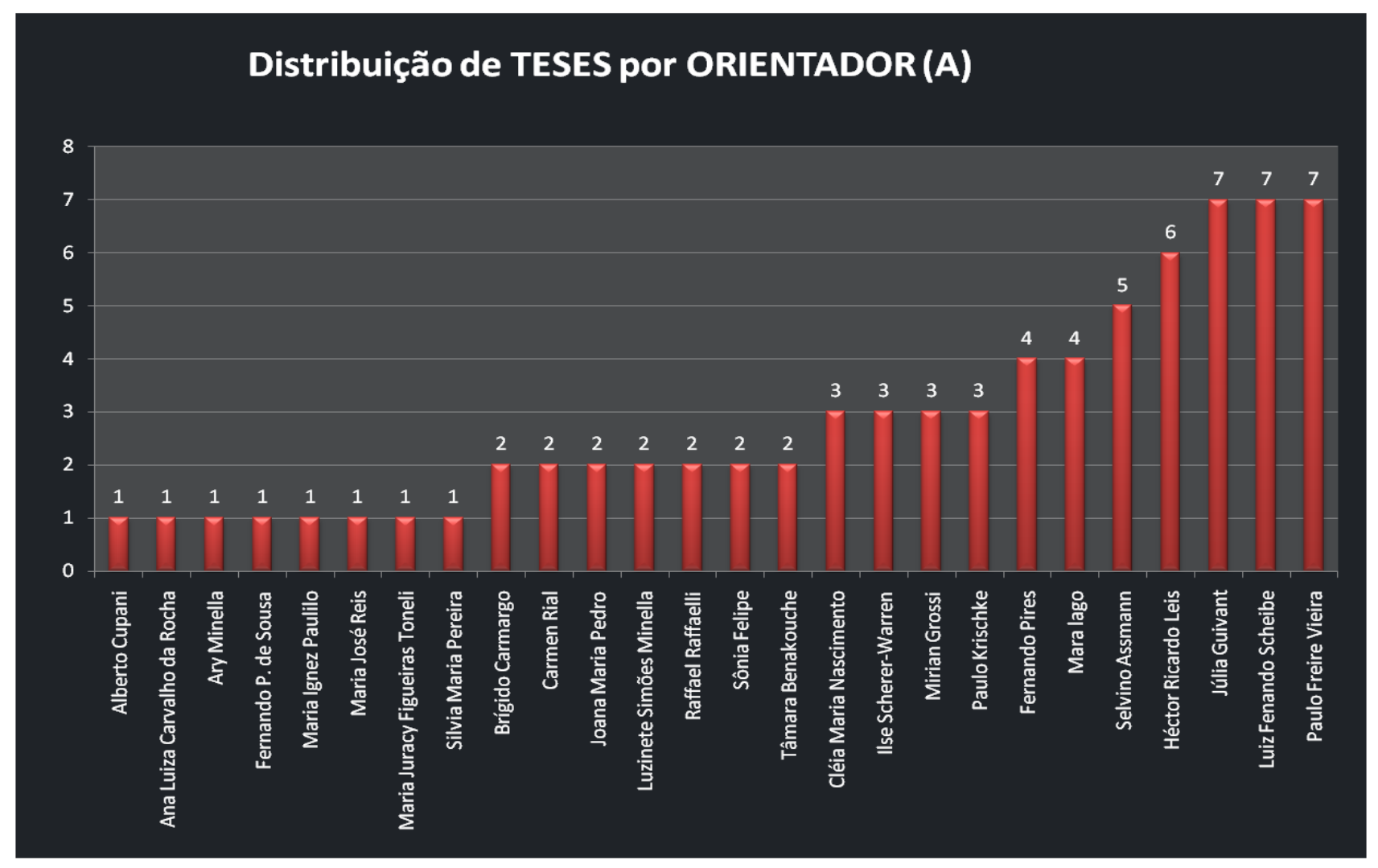

Gráfico 04: Número de teses orientadas por docente - orientador (a) Fonte: Elaborado a partir do site do PPGICH - UFSC (2008). 
Os três (3) professores que mais orientaram estão vinculados à temática de meio ambiente; as razões foram explicitadas anteriormente. Segundo a proposição da CAPES, há necessidade de um equilíbrio na distribuição das orientações. Acredita-se que tal distribuição tenda a um equilíbrio, na medida em que houver o acréscimo das duas outras áreas, Condição Humana e Modernidade e Estudos de Gênero. Além disso, o critério de seleção dos estudantes e a disponibilidade dos professores são variáveis igualmente importantes.

O gráfico 05 mostra a distribuição de co-orientação de mais de dois trabalhos.

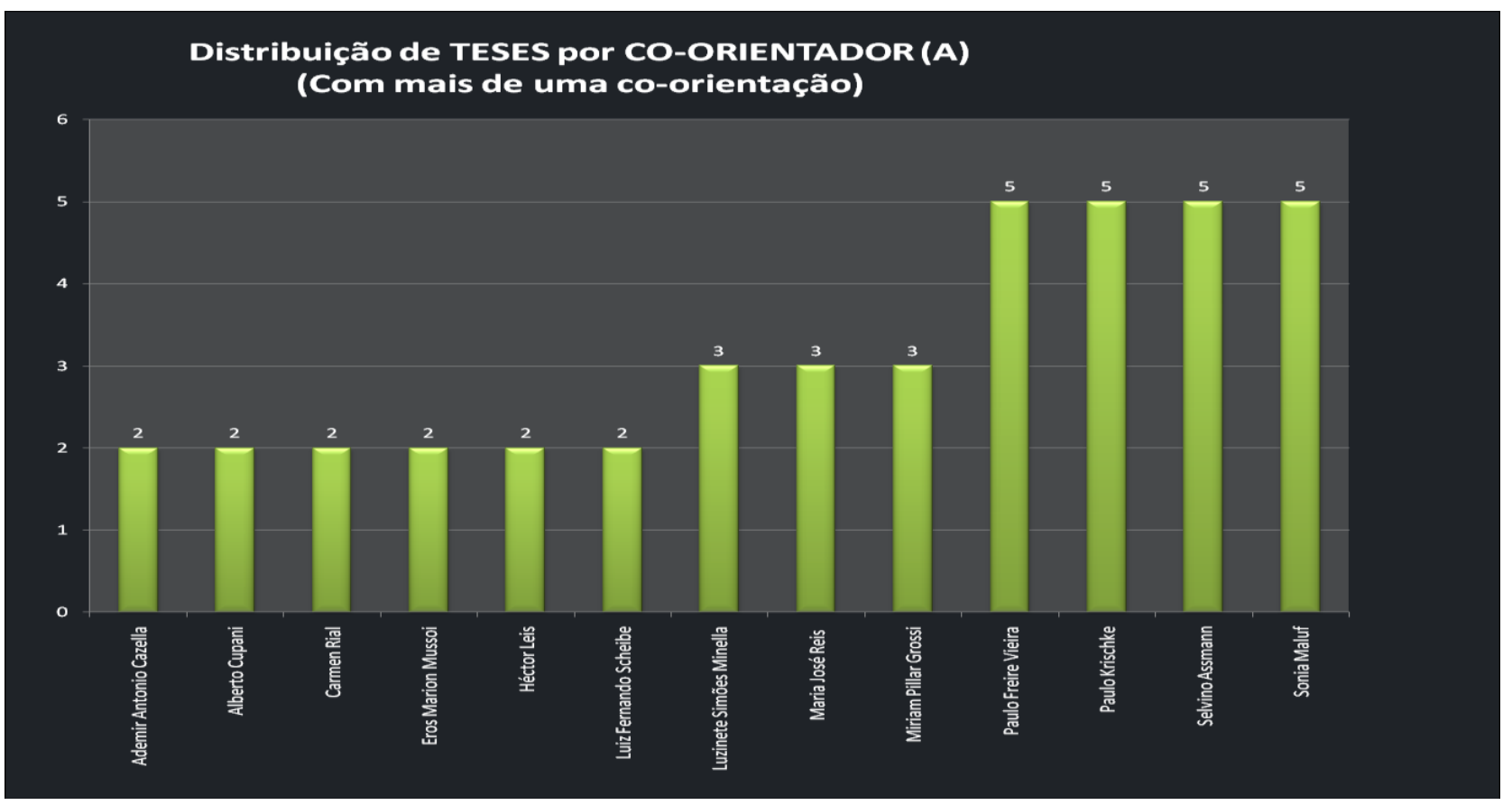

Gráfico 05: Número de teses orientadas por docente - co-orientador (a) Fonte: Elaborado a partir do site do PPGICH - UFSC (2008).

Observa-se que, entre os professores que co-orientaram mais de um trabalho, há uma elevada concentração. É possível distinguir dois pólos: vinte e um (21) trabalhos foram co-orientados por nove (9) professores (com dois (2) ou três (3) co-orientações); vinte (20) teses foram co-orientadas por quatro (4) professores (com cinco (5) coorientações). Das setenta e quatro (74) teses defendidas no período em estudo (19992008), quarenta e uma (41) foram co-orientadas por treze (13) professores e, as demais, por outros trinta e três (33). O quadro 01 relaciona o nome dos trinta e três (33) professores que co-orientaram um (1) trabalho. 


\begin{tabular}{|l|l|l||}
\hline \multicolumn{2}{|c|}{ Relação de co-orientadores com UMA Co-orientação } \\
\hline \hline Alai Garcia Diniz & Ivo Marcos Theis & Nelly Novaes Coelho \\
\hline \hline Alexandre Fernandez Vaz & Jean-Philippe Tonneau & Paulo Belli Filho \\
\hline \hline Antonio C. Diegues & João de Deus Medeiros & Pedro Leite da Silva Dias \\
\hline \hline Bernard Roux & Julia Guivant & Rafael Raffaelli \\
\hline \hline Carmen Lúcia Soares & Lino Fernando Lindolfo Lohn & Reinaldo Pereira e Silva \\
\hline \hline César Augusto Pompêo & Louise Lhullier & Ricardo Ventura Santos \\
\hline Erni Seibel & Luiz A. Proença & Sandra Nahas \\
\hline \hline Esther Jean Langdon & Luz Carlos Mior & Silvio Coelho dos Santos \\
\hline \hline Franz Brüseke & Mara Coelho & Sônia Felipe \\
\hline \hline Gilberto F. dos Santos & Maria Bernadete Ramos Flores & Tamara Benakouche \\
\hline \hline Gilson Fernando Queluz & Maria Teresa Castelo Branco & Terry Marsden \\
\hline
\end{tabular}

Quadro 01: Número de teses co-orientadas por docente com uma co-orientação

Fonte: Elaborado a partir do site do PPGICH - UFSC (2008).

O professor cuja soma de orientações e co-orientações contribuiu com o maior número de teses foi o Dr. Paulo Freire Vieira, que participou de doze (12) trabalhos. Em segundo, está o professor Selvino Assmann, com dez (10) colaborações. Estes professores também se vinculam a outros programas do Centro de Filosofia e Ciências Humanas da UFSC. O primeiro vincula-se ao Programa de Sociologia e Ciência Política, e o professor Dr. Selvino Assmann liga-se ao Programa de Filosofia.

O site do Programa Interdisciplinar apresenta trinta e cinco (35) professores vinculados, que são categorizados como permanentes, participantes e visitantes. O total de cinqüenta e seis (56) professores que atuaram orientando ou co-orientando é justificado pela especificidade do programa interdisciplinar, que demanda uma diversidade grande de profissionais oriundos de diferentes áreas. Dessa forma, é admissível que o co-orientador pertença a outros programas ou instituições.

\section{FORMAÇÃO ACADÊMICA DOS DOCENTES E DOS EGRESSOS}

Os dados sobre a formação dos docentes e egressos foram obtidos por meio do Currículo Lattes, presente no site do Conselho Nacional de Pesquisa - CNPq. A classificação das áreas e grandes áreas também seguiram a orientação do referido site. 
Quanto ao universo e amostra, este estudo abrange:

\begin{tabular}{|c|c|c|}
\cline { 2 - 3 } \multicolumn{1}{c|}{} & Universo & Amostra $^{8}$ \\
\hline Docentes & $76^{9}$ & 63 \\
\hline Egressos & 74 & 68 \\
\hline
\end{tabular}

É importante considerar que, entre os docentes, alguns realizaram o doutorado sem cursar o mestrado; há outros que possuem mais de um mestrado. Outra situação recorrente, há docentes e egressos com mais de uma graduação.

Os gráficos 06, 07 e 08 sintetizam a formação acadêmica do corpo docente do Programa, no que tange ao doutorado, mestrado e graduação ${ }^{10}$.

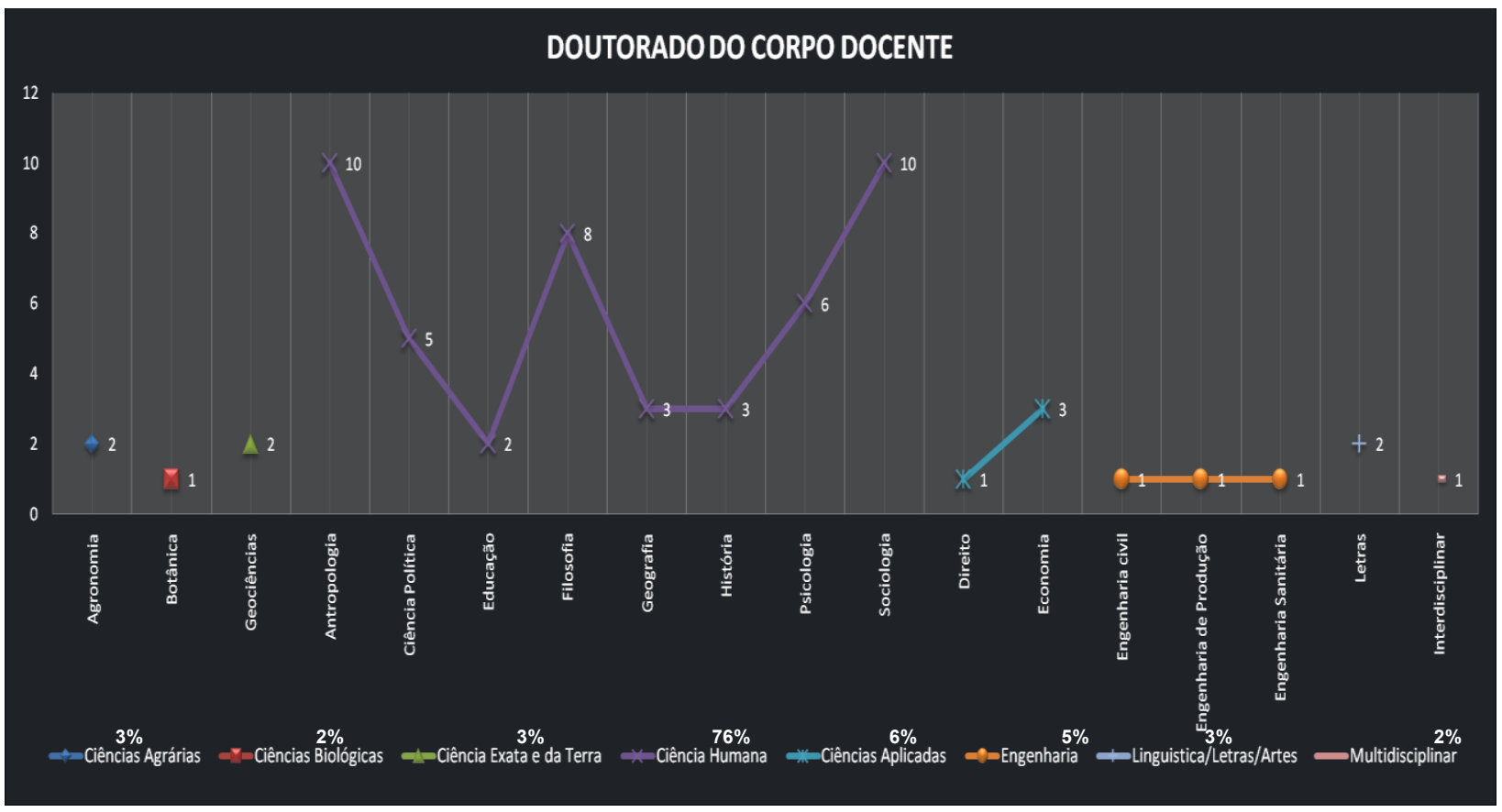

Grafico 06: Formação Acadêmica do Corpo Docente - Doutorado

Fonte: Elaborado a partir do site do PPGICH - UFSC (2008); CNPq - Lattes (2009).

O gráfico 06 mostra o predomínio da grande área Ciências Humanas (76\%) no doutorado dos professores, com destaque para as áreas de Antropologia (10), Sociologia (10), Filosofia (8), Psicologia (6) e Ciências Sociais (5).

\footnotetext{
${ }^{8}$ Há um total de treze (13) professores e seis (6) egressos que não foram contemplados nesta pesquisa porque seus currículos não puderam ser acessados.

${ }^{9}$ Constam neste total (76), todos os professores com vínculo de permanência, participante, visitante ou que orientaram ou co-orientaram alguma tese.

${ }^{10} \mathrm{O}$ pós-doutorado e a especialização não foram considerados nesta pesquisa porque, muitas vezes, as informações disponibilizadas não eram suficientes para a classificação das áreas e grandes áreas.
}

Cad. de Pesq. Interdisc. em Ci-s. Hum-s., Florianópolis, v.10, n.97, p. 5-26, jul./dez. 2009 


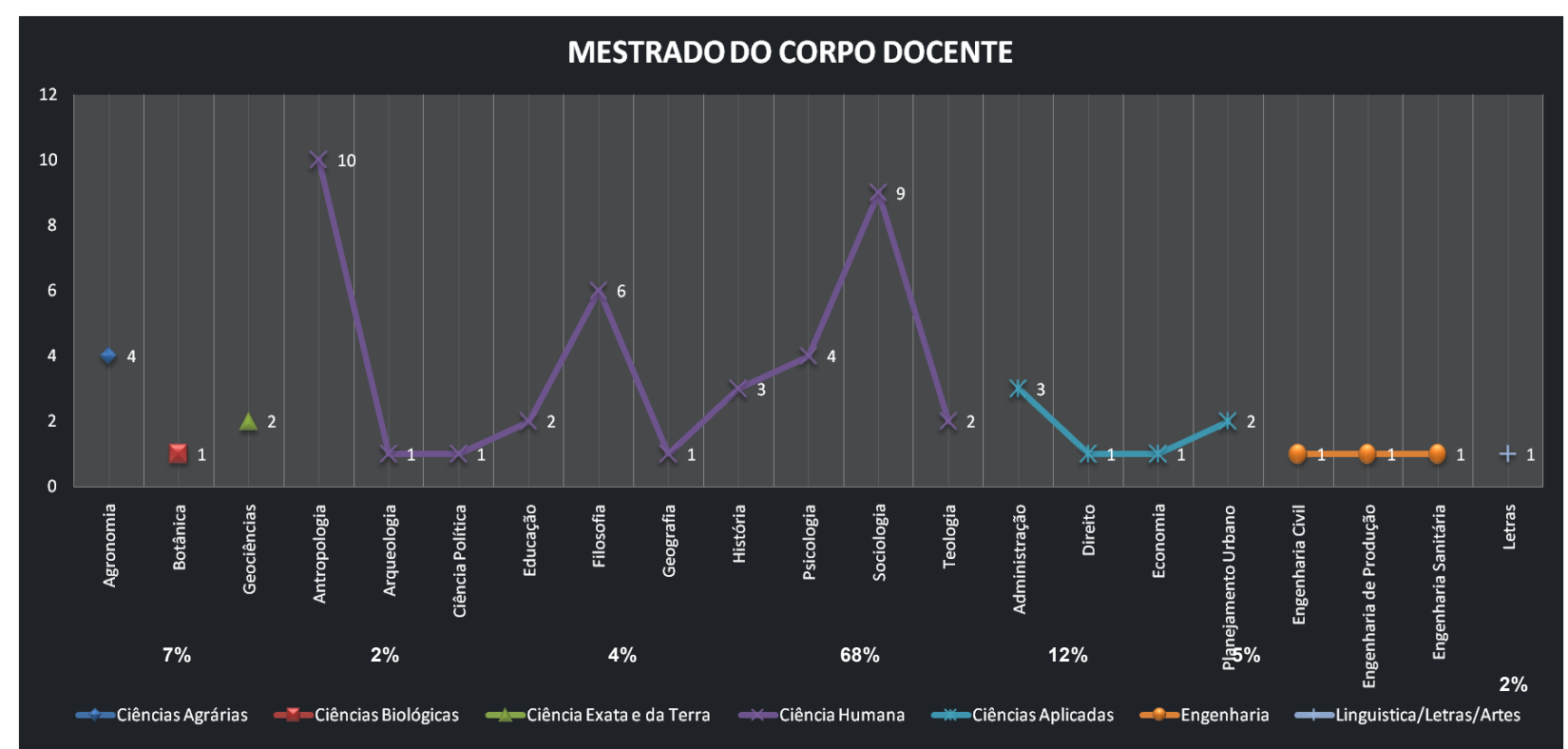

Gráfico 07: Formação Acadêmica do Corpo Docente - Mestrado

Fonte: Elaborado a partir do site do PPGICH - UFSC (2008); CNPq - Lattes (2009).

O gráfico 07 mantém o predomínio da grande área - Ciências Humanas (68\%), e as áreas com maior número de incidência são: Antropologia (10), Sociologia (9), Filosofia (6), Psicologia (4). A área de Agronomia se destaca com quatro (4) na formação de professores.

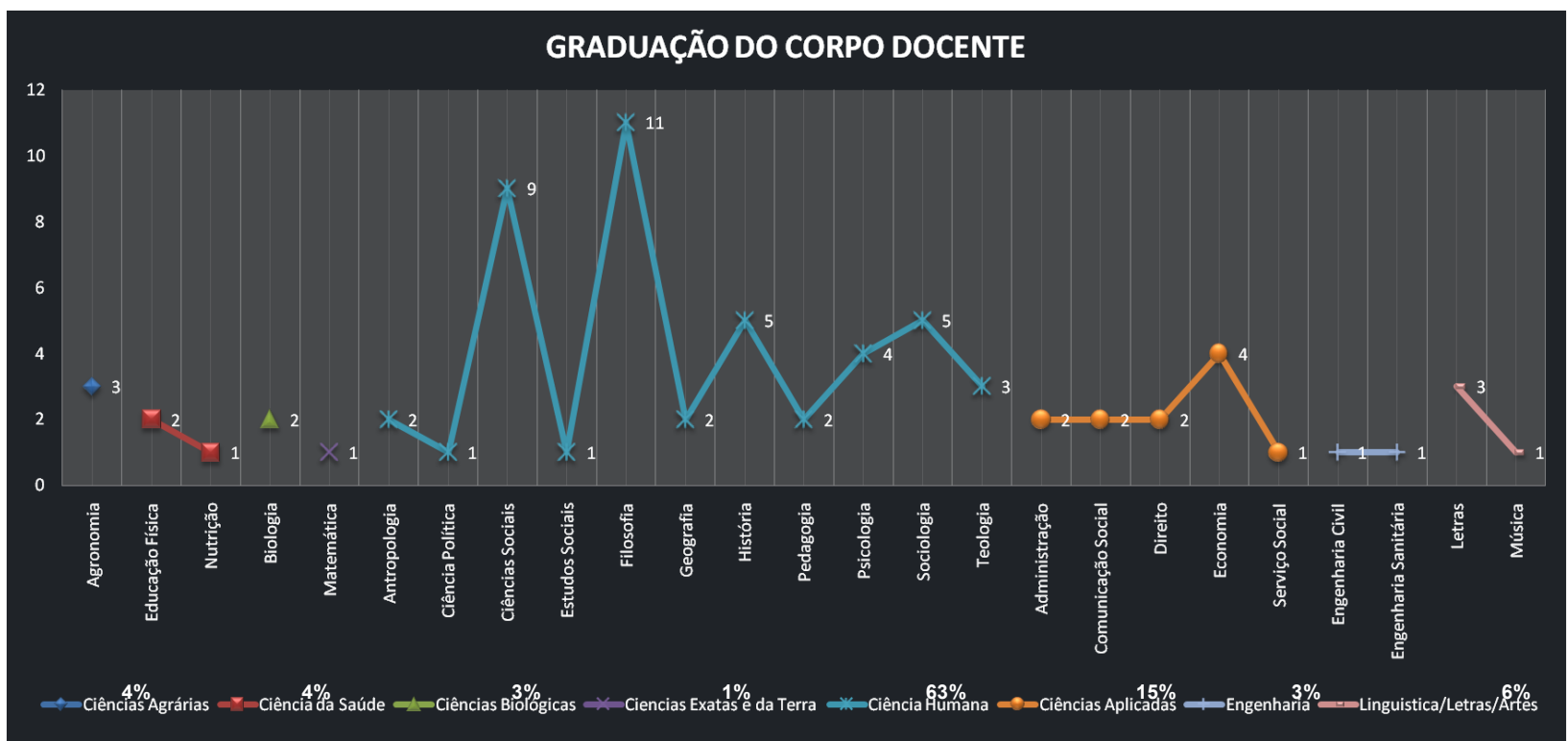

Gráfico 08: Formação Acadêmica do Corpo Docente - Graduação

Fonte: Elaborado a partir do site do PPGICH - UFSC (2008); CNPq - Lattes (2009).

Cad. de Pesq. Interdisc. em Ci-s. Hum-s., Florianópolis, v.10, n.97, p. 5-26, jul./dez. 2009 
No gráfico 08 é confirmada a predominância da grande área - Ciência Humanas (63\%). As áreas de Filosofia (11), Ciências Sociais (9), Sociologia (5), História (5) e Psicologia (4) compõem o maior número de graduações dos professores na referida grande área. Destacam-se, também, Economia, com quatro (4) professores formados, na grande área Ciências Aplicadas (15\%).

Os gráficos 09 e 10 trazem a formação acadêmica dos alunos egressos do Programa até o ano de 2008.

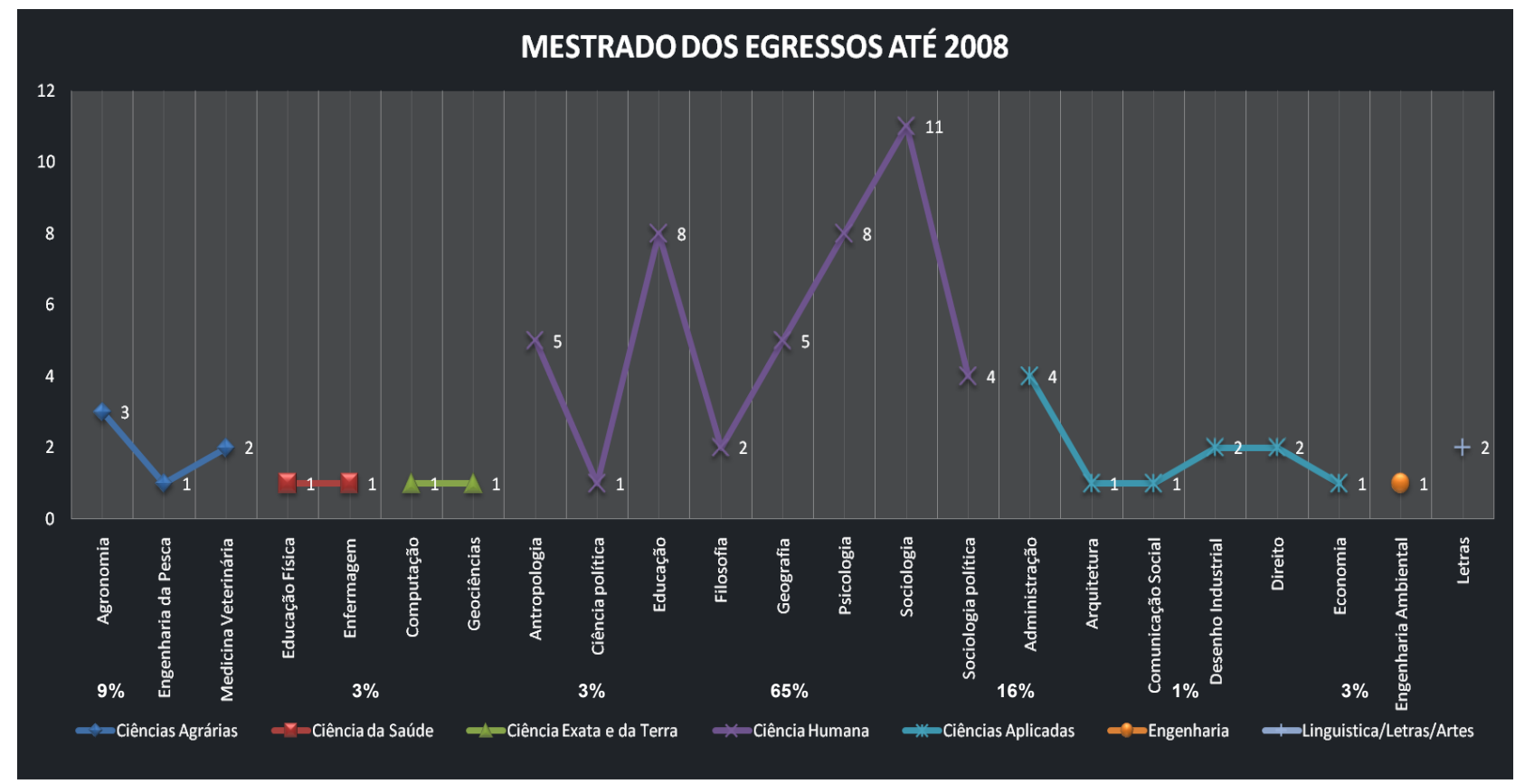

Gráfico 09: Formação Acadêmica dos Egressos - Mestrado

Fonte: Elaborado a partir do site do PPGICH - UFSC (2008); CNPq - Lattes (2009).

A grande área - Ciências Humanas - tem $65 \%$, sendo que as áreas mais cursadas no mestrado pelos egressos é Sociologia (11), seguida por Educação (8), Psicologia (8), Antropologia (5), Geografia (5) e Sociologia Política (4). O curso de Administração (4) destaca-se na grande área de Ciências Aplicadas (16\%).

O gráfico 10 apresenta a formação acadêmica dos egressos em nível de graduação 


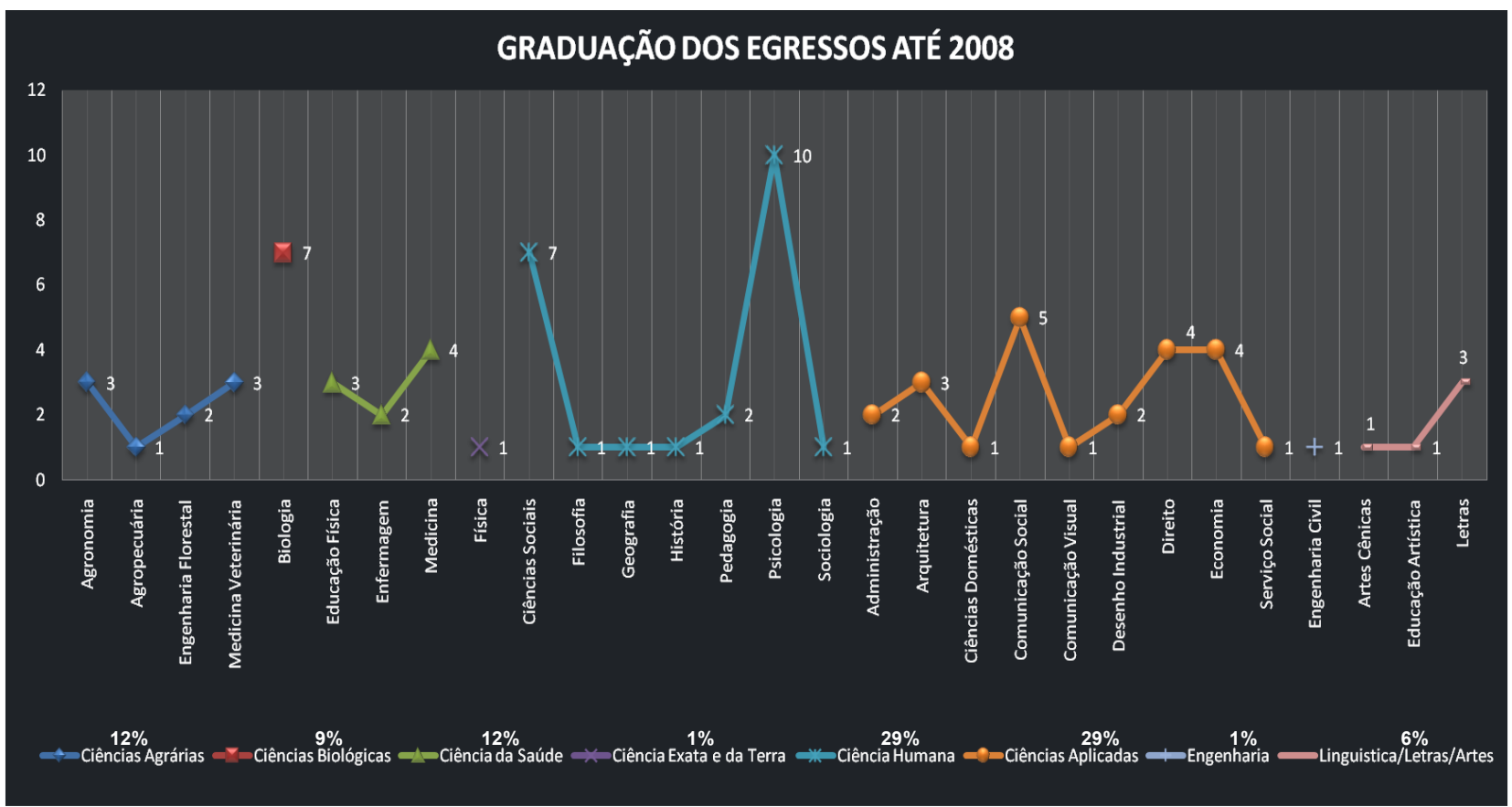

Gráfico 10: Formação Acadêmica dos Egressos - Graduação

Fonte: Elaborado a partir do site do PPGICH - UFSC (2008); CNPq - Lattes (2009).

O gráfico da graduação dos egressos mostra uma diversidade mais equilibrada na formação destes. As grandes áreas de Ciências Humanas e de Ciências Aplicadas coincidem com 29\% cada uma. Ciências Agrárias e Ciências da Saúde apresentam $12 \%$.

Destacam-se as seguintes áreas: Psicologia (10), Ciências Sociais (7), Biologia (7), Comunicação Social (5), Direito, Economia e Medicina (4).

A seguir são apresentados dois quadros que sintetizam os principais resultados. O quadro 02 mostra os resultados comparativos entre as grandes áreas [definição obtida segundo o CNPq]; o quadro 03 apresenta os principais resultados em relação às áreas. 


\begin{tabular}{|c|c|c|c|c|c|c|c|c|}
\hline $\begin{array}{l}\text { Ciências } \\
\text { Agrárias }\end{array}$ & $\begin{array}{l}\text { Ciências } \\
\text { da } \\
\text { Saúde }\end{array}$ & $\begin{array}{l}\text { Ciências } \\
\text { Biológicas }\end{array}$ & $\begin{array}{l}\text { Ciências } \\
\text { Exatas e } \\
\text { da Terra }\end{array}$ & $\begin{array}{l}\text { Ciências } \\
\text { Humana }\end{array}$ & $\begin{array}{l}\text { Ciências } \\
\text { Aplicadas }\end{array}$ & Engenharia & $\begin{array}{l}\text { Linguistica/ } \\
\text { Letras/Artes }\end{array}$ & Multidisciplinar \\
\hline \multicolumn{9}{|c|}{ Corpo Docente - Doutorado } \\
\hline 2 & 0 & 1 & 2 & 47 & 4 & 3 & 2 & 1 \\
\hline $3 \%$ & $0 \%$ & $2 \%$ & $3 \%$ & $76 \%$ & $6 \%$ & $5 \%$ & $3 \%$ & $2 \%$ \\
\hline \multicolumn{9}{|c|}{ Corpo Docente - Mestrado } \\
\hline 4 & 0 & 1 & 2 & 39 & 7 & 3 & 1 & 0 \\
\hline $7 \%$ & $0 \%$ & $2 \%$ & $4 \%$ & $68 \%$ & $12 \%$ & $5 \%$ & $2 \%$ & $0 \%$ \\
\hline \multicolumn{9}{|c|}{ Corpo Docente - Graduação } \\
\hline 3 & 3 & 2 & 1 & 45 & 11 & 2 & 4 & 0 \\
\hline $4 \%$ & $4 \%$ & $3 \%$ & $1 \%$ & $63 \%$ & $15 \%$ & $3 \%$ & $6 \%$ & $0 \%$ \\
\hline \multicolumn{9}{|c|}{ Egresso - Mestrado } \\
\hline 6 & 2 & 0 & 2 & 44 & 11 & 1 & 2 & 0 \\
\hline $9 \%$ & $3 \%$ & $0 \%$ & $3 \%$ & $65 \%$ & $16 \%$ & $1 \%$ & $3 \%$ & $0 \%$ \\
\hline \multicolumn{9}{|c|}{ Egresso - Graduação } \\
\hline 9 & 9 & 7 & 1 & 23 & 23 & 1 & 5 & 0 \\
\hline $12 \%$ & $12 \%$ & $9 \%$ & $1 \%$ & $29 \%$ & $29 \%$ & $1 \%$ & $6 \%$ & $0 \%$ \\
\hline
\end{tabular}

Quadro 02: Síntese das Grandes Áreas na Formação Acadêmica dos Professores e dos Egressos Fonte: Elaborado a partir do site do PPGICH - UFSC (2008); CNPq - Lattes (2009).

Do quadro 02 pode-se concluir que há um predomínio da grande área Ciências Humanas. A grande área Ciências Aplicadas está em segundo lugar, cujo destaque pertence à graduação dos egressos. As Ciências Agrárias, que ocupa o terceiro lugar na ordem de representação na formação acadêmica do Programa Interdisciplinar, também tem o maior percentual na graduação dos egressos. As Ciências Exatas e da Terra e as Engenharias possuem os menores índices de representatividade.

O quadro 03 , a seguir, apresenta uma comparação dos principais resultados das diferentes áreas de conhecimentos entre todos os níveis acadêmicos dos docentes e dos egressos. Foram considerados somente os resultados que obtiveram frequência 
acima de 4. O propósito deste quadro é ressaltar o perfil predominante quanto à formação acadêmica por área e nível de formação.

\begin{tabular}{|c|c|c|c|c|c|}
\hline Áreas & $\begin{array}{l}\text { Docente - } \\
\text { Doutorado }\end{array}$ & $\begin{array}{l}\text { Docente - } \\
\text { Mestrado }\end{array}$ & $\begin{array}{l}\text { Docente - } \\
\text { Graduação }\end{array}$ & $\begin{array}{l}\text { Egresso - } \\
\text { Mestrado }\end{array}$ & $\begin{array}{l}\text { Egresso - } \\
\text { Graduação }\end{array}$ \\
\hline Administração & & & & 4 & \\
\hline Agronomia & & 4 & & & \\
\hline Antropologia & 10 & 10 & & 5 & \\
\hline Biologia & & & & & 7 \\
\hline $\begin{array}{l}\text { Ciências } \\
\text { Sociais }\end{array}$ & 5 & & 9 & & 7 \\
\hline $\begin{array}{c}\text { Comunicação } \\
\text { Social }\end{array}$ & & & & & 5 \\
\hline Direito & & & & & 4 \\
\hline Economia & & & 4 & & 4 \\
\hline Educação & & & & 8 & \\
\hline Filosofia & 8 & 6 & 11 & & \\
\hline Geografia & & & & 5 & \\
\hline História & & & 5 & & \\
\hline Medicina & & & & & 4 \\
\hline Psicologia & 6 & 4 & 4 & 8 & 10 \\
\hline Sociologia & 10 & 9 & 5 & 11 & \\
\hline $\begin{array}{l}\text { Sociologia } \\
\text { Política }\end{array}$ & & & & 4 & \\
\hline
\end{tabular}

Quadro 03: Síntese dos Principais Resultados das Áreas na Formação Acadêmica dos Professores e dos Egressos

Fonte: Elaborado a partir do site do PPGICH - UFSC (2008); CNPq - Lattes (2009).

Do quadro 03 pode-se concluir que, em nível de pós-graduação, a Antropologia e a Sociologia são as mais recorrentes entre os docentes e egressos. Já em nível de graduação, a Filosofia se destaca entre os docentes, e a Psicologia, entre os alunos.

Com relação à Filosofia, destaca-se o número de professores com formação nesta área, sobretudo na graduação. Ao mesmo tempo, não há um número mínimo de quatro egressos com tal formação no período analisado. 
A Psicologia é a única área que é representada em todos os níveis, tanto para os docentes quanto para os egressos. Considerando que a graduação em Ciências Sociais abrange Sociologia, Ciência Política e Antropologia, pode-se concluir que, assim como a Psicologia, as áreas Sociologia e Antropologia também têm representatividade em todos os níveis.

A graduação predominante entre os docentes é a Filosofia e, entre os egressos, é a psicologia. No caso do mestrado, prevalece a Antropologia entre os docentes e a sociologia entre os egressos.

\section{RECORRÊNCIA DAS PALAVRAS-CHAVE}

Com o objetivo de identificar os principais temas abordados pelos egressos, foram observadas as palavras ou expressões destacadas nas palavras-chave de suas teses. Entende-se que estas devem abranger a essencialidade do que é abordado no conjunto do trabalho. A fonte dos dados foi o site do Programa Interdisciplinar, especificamente nos resumos das teses.

A seleção e a organização das palavras que constam no quadro 04 partem, principalmente, da subjetividade das autoras deste artigo. Dessa forma, outros trabalhos com o mesmo propósito poderiam chegar a conclusões diferentes. De qualquer modo, entende-se como relevante esta iniciativa para se obter um perfil dos grandes temas abordados no Programa.

Como parte da seleção das palavras ou expressões, excluiu-se as que se referiam a localidades, verbos isolados, nomes de autores e setores econômicos. No que diz respeito à organização, optou-se pela divisão a partir de grandes questões, a fim de atribuir uma estruturação à seleção. As expressões ou palavras compostas podem representar até duas questões. Por exemplo, desenvolvimento sustentável está categorizado como questão ambiental e questão do desenvolvimento. Quando houve dúvidas na categorização das palavras ou expressões, recorreu-se ao resumo das teses para auxiliar no melhor enquadramento. Exemplo disso foi a palavra 
subjetividade, que poderia permear grande parte das questões. Ao investigar os resumos, constatou-se que foi citada na tese sobre a questão do trabalho.

É importante frisar, também, que a distinção em questões não obedece à separação formal entre as Áreas de Concentração do Programa. Uma mesma questão pode ter sido abordada pelas diferentes áreas. Segue o quadro 04 do perfil temático do Programa.

\section{QUESTÃO AMBIENTAL}

Agroecologia (1) - Água (1) - Ambientalismo (2) - Avaliação Ambiental Estratégica (1) - Ciência econômica ambiental (1) - Conflitos ambientais (2) - Conservação da Biodiversidade (1) conservação da natureza (1) - Desenvolvimento Sustentável (5) - Ecodesenvolvimento (3) Ecologia (3) - Ecotécnicas (1) - Educação Ambiental (1) - Educação para o Ecodesenvolvimento (1) - Etnoambiental (1) - Extração predatória (1) - Gestão Ambiental (2) - Impactos

$49 \quad 14,9 \%$ Socioambientais (1) - Intercâmbio eco-econômico (1) - Justiça Intergeracional (1) - Legislação Ambiental (1) - Meio Ambiente (2) - Orgânica (1) - Percepção de Risco (2) - Percepção Sócioambiental (1) - Previsão de Enchente (1) - Previsão do Tempo (1) - Problemas ambientais (1) - Proteção Ambiental (2) - Recursos naturais (1) - Sustentabilidade (4) - Vegetação (1).

\section{QUESTÃO DO DESENVOLVIMENTO}

Desenvolvimento (4) - Desenvolvimento Rural (2) - Desenvolvimento Sustentável (5) - Dinâmica Territorial (1) - Ecodesenvolvimento (3) - Economia (1) - Economia Neoclássica versus Economia sistêmica (1) - Economia Solidária (1) - Educação para o Ecodesenvolvimento (1) - Encontros Turísticos (1) - Gestão de Recursos Turísticos (1) - Gestão Participativa (1) - Intercâmbio ecoeconômico (1) - Moeda Social (1) - Reestruturação produtiva (1) - Sistema de Produção Flexível (1) - Território (1) - Turismo (1) - Turistas (1).

\section{QUESTÃO DA MODERNIDADE}

Ambiguidade (1) - Biodireito (1) - Bioética (2) - Biopoder (1) - Biotecnologia (1) - Comunicação (1) - Concepções de Natureza (1) - Condição humana (1) - Globalização (1) - Modernidade (8) Morte (1) - Natureza (1) - Natureza (1) - Razão Instrumental (1) - Razão Crítica (1) - Razão Intuitiva (1) - Razão Pública (1) - Vida (3) - Vida Cotidiana (1).

\section{QUESTÃO RURAL}

Agricultura (1) - Agricultura Familiar (7) - Agroecologia (1) - Agroindústria (2) - Agrovilas (1) Alimentação (1) - Cooperação agrícola (1) - Desenvolvimento Rural (2) - Ensino Técnico Agrícola (1) - Escola Agrícola (1) - Irrigação (1) - MST (2) - Produção Orgânica (1) - Reassentamento Rural (1) - Rural (3) - Usos da terra (1).

\section{QUESTÃO POLÍTICA}

Autonomia (1) - Auto-organização (1) - Cidadania (4) - Comunicação Intersubjetiva (1) -

Congresso Nacional (1) - Democracia (3) - Esfera Pública (1) - Espaço Público Urbano (1) -

Estado de Direito (1) - Exílio (1) - Movimento Feminista (1) - MST (2) - ONGs (1) - Política (3) -

Política Educacional (1) - Políticas Públicas (3) - Sujeitos em Movimento (1).

\section{QUESTÃO CULTURAL}

Afro-brasileiras (1) - Arquétipos (2) - Artesanato (1) - Conhecimento Popular (1) - Cultura (3) Cultura Material (1) - Cultura Popular (1) - Estereotipia (1) - Estigmatização (1) - Etnia (1) - 
Etnoambiental (1) - Etnohistória (1) - Identidade (3) - Imaginário (1) - índios Guarani (1) - Indústria Cultural (1) - Mito (1) - Mito do Herói (1) - Patrimônio Cultural (1) - Símbolo (1).

\section{QUESTÃO DA SAÚDE}

Aids (1) - Anencefalia (1) - Corpo (2) - Corpo Vivido (1) - Direitos Reprodutivos (1) Epidemiologia (1) - Intoxicação Alimentar (1) - Patentes de Seres Vivos (1) - Psicanálise (1) Psicologia (1) - Psicologia social (1) - Psicoterapia (1) - Psiquiatria (1) - Reprodução Humana (1) Risco e Trânsito (1) - Saúde (1) - Saúde Mental (1) - Serviços Residenciais Terapêuticos (1) Suicídio (1) - Tabaco (1) - Tabagismo (1).

\section{QUESTÃO DE GÊNERO}

Campo Feminista Brasileiro (1) - Casamento (2) - Conjugalidade (1) - Encontros Feministas (1) Estudos de Gênero (2) - Estudos Feministas (1) - Estudos Gays e Lésbicos (1) - Famílias (1) Feminino (1) - Gênero (4) - Relações de gênero (1) - Teoria de gênero (1) - Teoria Feminista (1) -

Teorias Feministas (1).

\section{QUESTÃO DA CIÊNCIA E TECNOLOGIA}

Biotecnologia (1) - Campo Científico (1) - Campo Feminista Brasileiro (1) - Ciência (2) - Ciência e Valores (1) - Ciência econômica ambiental (1) - Complexidade (1) - Interdisciplinaridade (3) Metodologia Científica (1) - Nanotecnologia (1) - Técnica (2) - Tecnociência (1).

\section{QUESTÃO DE SOCIALIZAÇÃO}

Individuação (2) - Jogos de Representação (1) - Representações Sociais (6) - Self (1) -

Socialização (1) - Sociedade (1) - Sociedade Contemporânea (1) - Sociedade dos Consumidores

$154,6 \%$ (1) - Sociedade global (1).

\section{QUESTÃO DA SEXUALIDADE}

Amor (1) - Direitos Sexuais (1) - Diversidade Sexual (1) - Estudos Gays e Lésbicos (1) Heterossexualidade (1) - Histórias de Referência (1) - Homossexualidades (2) - Menopausa (1) Orientação Homoerótica (1) - Roteiros Sexuais (1) - Sexualidade (3) - Sexualidade da Mulher (1).

\section{QUESTÃO URBANA}

Cidade (2) - Espaço Público Urbano (1) - Excesso de Velocidade (1) - Expansão Urbana (1) Igreja Católica (1) - Jovens (2) - Religiões (1) - Risco e Trânsito (1) - Televisão (1) - Trânsito (2) Trânsito e Velocidade (1).

\section{QUESTÃO EDUCACIONAL}

Conhecimento Popular (1) - Educação a Distância (1) - Educação Ambiental (1) - Educação para o Ecodesenvolvimento (1) - Ensino Técnico Agrícola (1) - Escola Agrícola (1) - Política Educacional (1) - Universidade Virtual (1).

\section{QUESTÃO DE DIREITO}

Biodireito (1) - Direito (1) - Direitos Humanos (1) - Direitos Reprodutivos (1) - Direitos Sexuais (1) - Justiça (1) - Justiça Intergeracional (1) - Legislação Ambiental (1).

\section{QUESTÃO ÉTICA}

Ética (2) - Ética Global (1) - Responsabilidade (1) - Senciência (1) - Valor (1) - Valor Inerente (1).

\section{QUESTÃO DE ESPACIALIDADE}

Design (1) - Espaço Público Urbano (1) - Espaços (1) - Interiores Domésticos (1) - Modo de vida (1) - Território (1) - Vida Cotidiana (1). 


\section{QUESTÃO DO TRABALHO}

Condições de Trabalho (1) - Geração de emprego (1) - Indivíduo-Trabalhador (1) - Mundo Trabalho (1) - Sociologia da Adversidade no Trabalho (1) - Subjetividade (1).

$6 \quad 1,8 \%$

\section{QUESTÃO DE REDE}

Rede Sociotécnica (3) - Redes (1).

$4 \quad 1,2 \%$

Quadro 04: Principais Temas Abordados nas Teses

Fonte: Elaborado a partir dos Resumos das Teses presentes nos Cadernos de Pesquisa Interdisciplinar em Ciências Humanas - UFSC (2009).

Entre as conclusões, pode-se afirmar que questão ambiental teve o maior número de adeptos. Com diferentes palavras e expressões, ela foi abordada nas palavras-chave quarenta e nove (49) vezes. As palavras mais citadas, com suas respectivas frequências, são: modernidade (8); agricultura familiar (7); representações sociais (6); desenvolvimento sustentável (5); sustentabilidade, cidadania, desenvolvimento e gênero (4).

\section{CONSIDERAÇÕES FINAIS}

O objetivo geral proposto neste artigo foi caracterizar o perfil do Programa de Doutorado Interdisciplinar em Ciências Humanas. Adotou-se como delimitação do perfil o reconhecimento dos atores e da construção do conhecimento, mediante a análise de frequência das teses defendidas; da formação acadêmica do corpo docente e dos egressos; da configuração do quadro de orientações e dos principais temas abordados nas teses.

Entende-se a caracterização do perfil é essencial e permite subsidiar mudanças, pontuar alguns obstáculos, reconhecer a trajetória que vem sendo construída, comparar e subsidiar novas estratégias para o curso, assim como analisar o programa interdisciplinar que se diferencia dos demais programas disciplinares. Não obstante as dificuldades da construção interdisciplinar, Fazenda (2008, p. 12) sustenta o sentido ambíguo de tal construção, enfatizando ser, ao mesmo tempo, um exercício que nos impele a "enfrentar o caos e a buscar a matriz de uma ordem, de uma idéia básica de 
organização. Navegar na ambiguidade exige aceitar a loucura que a atividade interdisciplinar desperta e a lucidez que ela exige".

Se a interdisciplinaridade "é essencialmente um processo que precisa ser vivido e exercido" (FAZENDA, 2001, p. 11), o Programa é um organismo vivo e em constante transformação. Sua trajetória vai sendo construída e dela deve-se apreender quais os movimentos e qual o rumo. Este estudo, então, buscou caracterizar parte do caminho percorrido pelos atores envolvidos no $\mathrm{PPGICH}$, e espera-se que a descrição quantitativa realizada torne-se um ponto de referência no avanço de uma avaliação crítica dos desafios enfrentados pelo Programa. 


\section{REFERÊNCIAS}

CADERNOS de Pesquisa Interdisciplinar em Ciências Humanas. Resumos das Teses. Disponível em: <http://www.periodicos.ufsc.br/index.php/cadernosdepesquisa/thesis>. Acesso em: abril de 2009.

CAPES - Coordenação de Aperfeiçoamento Pessoal de Nível Superior. Ciência caminha para a interdisciplinaridade (2008). Disponível em:

$<$ http://www.capes.gov.br/servicos/sala-de-imprensa/36-noticias/2451-ciencia-caminhapara-a-interdisciplinaridade-dizem-pesquisadores>. Acesso em: abril de 2009.

CNPq - Conselho Nacional de Desenvolvimento Científico e Tecnológico. Plataforma Lattes. Disponível em: <http://lattes.cnpq.br/>. Acesso em: abril de 2009.

FAZENDA, I. C. A. (Org.). Didática e interdisciplinaridade. 13. ed. Campinas, SP: Papirus, 2008. (Coleção Práxis).

FAZENDA, I. C. A. (Org.). Dicionário em construção: interdisciplinaridade. São Paulo: Cortez, 2001.

KLEIN, J. T. Interdisciplinarity: história, theory e pratice. Detroite: Wayne State University Press, 1990.

MALHEIROS, T. F.; PHILIPPI Jr., A.. Uma visão crítica da prática interdisciplinar. In: PHILIPPI Jr., A. et al. (Ed.). Interdisciplinaridade em Ciências Ambientais. São Paulo: Signus Editora, 2000. p. 147-155.

PAVIANI, J. Interdisciplinaridade: conceitos e distinções. 2. ed. rev. Caxias do Sul, RS: Educs, 2008.

PPGICH-UFSC - Programa de Pós-graduação Interdisciplinar em Ciências Humanas, Universidade Federal de Santa Catarina. Disponível em:

<http://www.cfh.ufsc.br/ dich/index.htm>. Acesso em: dezembro de 2008.

PPGICH-UFSC - Programa de Pós-graduação Interdisciplinar em Ciências Humanas da Universidade Federal de Santa Catarina. Regimento. Disponível em:

$<$ http://www.cfh.ufsc.br/ dich/regimento.htm>. Acesso em: outubro de 2009.

Artigo:

Recebido em: 06/09/2009

Aceito em: 09/11/2009 